\title{
Aerosol scattering and absorption during the EUCAARI-LONGREX flights of the Facility for Airborne Atmospheric Measurements (FAAM) BAe-146: can measurements and models agree?
}

\author{
E. J. Highwood ${ }^{1}$, M. J. Northway ${ }^{1}$, G. R. McMeeking ${ }^{2, *}$, W. T. Morgan ${ }^{2}$, D. Liu ${ }^{2}$, S. Osborne ${ }^{3}$, K. Bower ${ }^{2}$, H. Coe ${ }^{2}$, \\ C. Ryder ${ }^{1}$, and P. Williams ${ }^{2}$ \\ ${ }^{1}$ Department of Meteorology, University of Reading, Reading, UK \\ ${ }^{2}$ SEAS, University of Manchester, Manchester, UK \\ ${ }^{3}$ Met Office, Cardington, UK \\ * now at: Department of Atmospheric Science, Colorado State University, USA
}

Correspondence to: E. J. Highwood (dennisl@uw.edu)

Received: 27 April 2011 - Published in Atmos. Chem. Phys. Discuss.: 29 June 2011

Revised: 17 July 2012 - Accepted: 1 August 2012 - Published: 9 August 2012

\begin{abstract}
Scattering and absorption by aerosol in anthropogenically perturbed air masses over Europe has been measured using instrumentation flown on the UK's BAe-146-301 large Atmospheric Research Aircraft (ARA) operated by the Facility for Airborne Atmospheric Measurements (FAAM) on 14 flights during the EUCAARI-LONGREX campaign in May 2008. The geographical and temporal variations of the derived shortwave optical properties of aerosol are presented. Values of single scattering albedo of dry aerosol at $550 \mathrm{~nm}$ varied considerably from 0.86 to near unity, with a campaign average of $0.93 \pm 0.03$. Dry aerosol optical depths ranged from $0.030 \pm 0.009$ to $0.24 \pm 0.07$. An optical properties closure study comparing calculations from composition data and Mie scattering code with the measured properties is presented. Agreement to within measurement uncertainties of $30 \%$ can be achieved for both scattering and absorption, but the latter is shown to be sensitive to the refractive indices chosen for organic aerosols, and to a lesser extent black carbon, as well as being highly dependent on the accuracy of the absorption measurements. Agreement with the measured absorption can be achieved either if organic carbon is assumed to be weakly absorbing, or if the organic aerosol is purely scattering and the absorption measurement is an overestimate due to the presence of large amounts of organic carbon. Refractive indices could not be inferred conclusively due to this uncertainty, despite the enhancement in methodology com-
\end{abstract}

pared to previous studies that derived from the use of the black carbon measurements. Hygroscopic growth curves derived from the wet nephelometer indicate moderate water uptake by the aerosol with a campaign mean $f(\mathrm{RH})$ value (ratio in scattering) of 1.5 (range from 1.23 to 1.63 ) at $80 \%$ relative humidity. This value is qualitatively consistent with the major chemical components of the aerosol measured by the aerosol mass spectrometer, which are primarily mixed organics and nitrate and some sulphate.

\section{Introduction}

Atmospheric aerosol has a "direct effect" on climate through the scattering and absorption of radiation and "indirect effects" via changes to cloud microphysics and properties. These effects are potentially considerable but uncertain. The global mean direct radiative forcing from 1750 to 2005 due to all anthropogenic aerosol was estimated as $-0.5 \pm 0.4 \mathrm{~W} \mathrm{~m}^{-2}$ and the indirect effect as -0.7 (with a range from -1.1 to 0.4) $\mathrm{W} \mathrm{m}^{-2}$ (IPCC, 2007). Aerosol plays a particularly important role in producing regional radiative forcing (although this can have non-local climate impacts). In order to estimate the direct effect of any aerosol we must know their optical properties. At the most basic level this means being able to quantify the refractive index (itself a function 
of composition) as a function of wavelength, the size distribution, the influence of relative humidity and the mixing state (internal or external). These properties are included in, or predicted by, aerosol transport models, and regional and global climate models and used in satellite retrieval algorithms for aerosol optical depth or other quantities. Climate models generally require the mass extinction coefficient, single scattering albedo and phase function (or its simplified form the asymmetry parameter) as well as the hygroscopicity. In order to include the indirect effects, size distribution and activation information are also required. Each of these properties are a complex function of aerosol size, composition, and chemical and physical processing (including impacts of humidity and clouds).

Some models that include aerosol interactively compute internally the size distribution or loading of aerosol types and determine the radiative effect using Mie scattering code or similar approaches. Others will prescribe bulk aerosol optical properties based on measurements from field campaigns or derived measurements such as those from the AErosol RObotic NETwork (AERONET). Volume weighted mixing is often used to combine optical properties (for external mixtures) or refractive indices and density prior to scattering calculations (for internal mixtures) of aerosol components such as sulphates or black carbon (BC) (e.g. Chylek et al., 1988; Osborne et al., 2007; Cook et al., 2007). It is important to quantify the uncertainty with which we know firstly the refractive indices of individual aerosols as measured in the laboratory, and secondly, how mixing the components affects scattering and absorption. Several studies have examined "closure" for these optical properties, where measured values of scattering and absorption are compared with calculations of the same using chemical composition information, measured particle size and a scattering code (e.g. Cai et al., 2011; Sciare et al., 2005; Wex et al., 2002; Quinn and Coffman, 1998). However, for aerosol which includes black carbon, this has not previously been possible from the UK's BAe-146-301 large Atmospheric Research Aircraft (and rare on other airborne platforms) since measurement of BC mass has only been possible by analysing filter samples post-flight. Particularly in situations with low BC amount, the resulting $\mathrm{BC}$ mass has a very large uncertainty associated with it. As a result, the amount of $\mathrm{BC}$ used in the "model" aerosol has often been tuned to give closure on single scattering albedo as derived from in-situ scattering and absorption measurements. Cook et al. (2007) and Osborne et al. (2007) apply this technique to data from the FAAM platform, using filter measurements to check the consistency of the mass of $\mathrm{BC}$ required. However, the filter measurements themselves carry large uncertainties for low concentrations of BC. Fiebig et al. (2002) and Petzold et al. (2002) used similar techniques with data from the DLR-Falcon platform - although it is important to note that this platform uses a different instrument for absorption measurement which may reduce the measurement uncertainties somewhat compared to those on the FAAM.
The advent of the SP2 instrument (Stephens et al., 2003; Schwarz et al., 2006) on board the FAAM BAe-146 (McMeeking et al., 2010) has allowed consistent measurements of the mass of $\mathrm{BC}$ to be used alongside those of sulphates, organics and nitrates taken using the Time-of-Flight Aerosol Mass Spectrometer (ToF-AMS). For the first time from this platform we are then able to perform optical property closure studies without tuning the black carbon amount, and to quantify the degree to which we can bring models and measurements of aerosol scattering and absorption into agreement. Another recent addition to the FAAM BAe-146 platform, the wet nephelometer, allows further new possibilities for closure studies for aerosol optical properties in the ambient/wet environment. This study therefore presents a significant new body of data concerning hygroscopic and optical properties of aerosol in anthropogenically perturbed air masses. It should be noted that this combination of measurements is particularly appropriate for anthropogenic aerosol where the majority of aerosol mass can now be measured. As the AMS does not detect mineral dust or sea salt aerosol, and the SP2 was used only to detect BC, the analysis provided here is not likely to represent regions with high loadings of these undetected materials.

The FAAM BAe-146 data from the EUCAARILONGREX campaign presents an opportunity to explore the agreement possible between models and airborne measurements of optical properties for an anthropogenic aerosol of a variety of ages across north-west Europe. The use of in-situ black carbon measurements allows a more complete closure study than has been used in other studies using data from this, and other measurement platforms. Section 2 of this paper describes briefly the campaign meteorology, flights undertaken and instrumentation used, as well as the methodologies used to derive the aerosol optical properties that are presented in the rest of the paper. Section 3 presents the optical properties derived from the airborne measurements. Section 4 discusses measurements of the increased scattering by aerosol due to relative humidity and its effect on measured aerosol properties. Section 5 discusses Mie scattering calculations using chemical composition and size distribution and the success of optical closure experiments. The work is summarized and conclusions are drawn in Sect. 6.

\section{Flights and instrumentation}

\subsection{EUCAARI meteorology and flights}

During the EUCAARI-LONGREX campaign of May 2008, the FAAM BAe-146 made 15 flights generally consisting of $5 \mathrm{~h}$ sorties over central Europe or off the coast of the UK. The flights used in this paper (defined in Table 1) span the region $47-57^{\circ} \mathrm{N}$ and $12^{\circ} \mathrm{W}$ to $22^{\circ} \mathrm{E}$ and probed both the boundary layer and free troposphere in clean and polluted conditions. 
Table 1. Flights from May 2008 used in EUCAARI analysis. Classification according to Morgan et al. (2009): L1=LONGREX-1, L2 = LONGREX-2, L3 = LONGEX-3. * Not used for closure studies in Sect. 5.

\begin{tabular}{|c|c|c|c|}
\hline $\begin{array}{l}\text { Flight } \\
\text { number }\end{array}$ & $\begin{array}{l}\text { Date and } \\
\text { classification }\end{array}$ & General location & Comments \\
\hline B362 & 6 May a.m. (L1) & Germany/Belgium and N. Sea & \\
\hline B363 & 6 May p.m. (L1) & Germany/Belgium and N. Sea & \\
\hline B364 & 7 May p.m. (L1) & Southern Germany & \\
\hline B365 & 8 May (L1) & Eastern Europe and the Baltic Sea & \\
\hline B366 & 8 May (L1) & North-western Europe & PCASP QA failure* \\
\hline B367 & 9 May & Southern Germany & $\begin{array}{l}\text { DLR intercomparison } \\
\text { flight }\end{array}$ \\
\hline B368 & 10 May a.m. (L2) & Germany/Poland and Baltic coast & \\
\hline B369 & 10 May p.m. (L2) & Baltic Sea/Germany & \\
\hline B370 & 12 May a.m. (L2) & Germany, Netherlands and N. Sea & \\
\hline B371 & 12 May (L2) & Germany/Baltic Sea & \\
\hline B372 & 13 May a.m. (L2) & $\begin{array}{l}\text { Germany/Poland/Netherlands/ } \\
\text { East coast of UK }\end{array}$ & No BC data* \\
\hline B373 & 13 May a.m. (L2) & Southern UK coast & \\
\hline B374 & 14 May (L2) & $\begin{array}{l}\text { Irish sea and Atlantic ocean SW of } \\
\text { Ireland }\end{array}$ & \\
\hline B379 & 21 May (L3) & Germany/Netherlands/Belgium & \\
\hline B380 & 22 May (L3) & $\begin{array}{l}\text { Germany/Netherlands/Belgium and } \\
\text { Southern UK coast }\end{array}$ & \\
\hline
\end{tabular}

Flight patterns generally consisted of either north-south transects to cut across air mass gradients or east-west transects to follow the air mass trajectories. Aircraft manoeuvres included straight and level runs (SLRs) at a variety of altitudes within and above the boundary layer and deep profiles through the boundary layer at rates of $5 \mathrm{~m} \mathrm{~s}^{-1}$ above the boundary layer and $2.5 \mathrm{~m} \mathrm{~s}^{-1}$ within the boundary layer.

The meteorology of the EUCAARI-LONGREX campaign has been discussed extensively in Morgan et al. (2010a, b), McMeeking et al. (2010) and Hamburger et al. (2011) so will not be repeated here in detail. The majority of flights took place during a period dominated by a strong high surface pressure system positioned in the region of Denmark. Following Morgan et al. (2010a), the EUCAARI LONGREX period can be divided into 3 parts based on the dominant meteorology: LONGREX-1 (6-8 May 2008, flights B362$366)$ is defined by approximately zonal flow from east to west; during LONGREX-2 (10-14 May 2008, flights B369B374) the strong anticyclone was centered over Denmark and northern Germany resulting in more strongly curving anticyclonic flow; whilst finally LONGREX-3 (19-20 May, flights B379-380) was characterized by building high pressure following the passage of a weak frontal system across northern Europe with predominantly easterly flow. As a representative example of the flow during the majority of the flights discussed in this paper, Fig. 1 shows the synoptic situation during the LONGREX-2 period as defined by the mean sea level pressure from ECMWF analyses at 12:00 UTC on 13 May 2008. Flights during LONGREX-2 in particular were designed to follow the air mass from east to west across

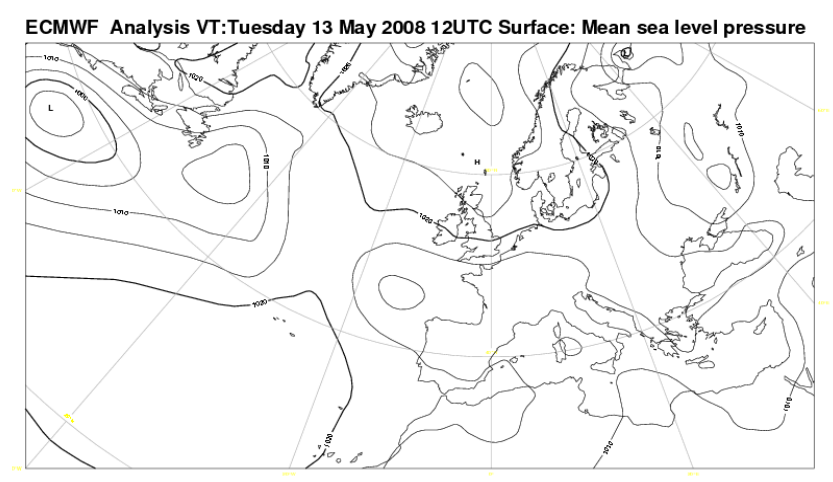

Fig. 1. Mean sea-level pressure from ERA-Interim data on 13 May 2008 during LONGREX-2 period.

north-western Europe, sampling increasingly aged aerosol as well as that from local sources, such that any influences of aging/transport/emissions on optical properties and chemical composition might be determined.

\subsection{Instrumentation and derived aerosol properties}

The FAAM BAe-146 carries a considerable range of instrumentation. Only the instrumentation that is particularly relevant for optical property studies is described here. More comprehensive discussion of the full instrumentation can be found in Johnson et al. (2000) and Osborne et al. (2007). The size range and estimated accuracy of the instruments used in this paper is summarised in Table 2 . 
Table 2. Summary of the in-situ aerosol sampling instrumentation on the FAAM BAe146 during the EUCAARI campaign.

\begin{tabular}{|c|c|c|c|}
\hline Quantity measured & Instrument & Size range & Sensitivity and/or Uncertainty \\
\hline $\begin{array}{l}\text { Aerosol optical diameter and } \\
\text { concentration }\end{array}$ & $\begin{array}{l}\text { Passive cavity aerosol } \\
\text { spectrometer probe } \\
\text { (PCASP-100x) }\end{array}$ & $\begin{array}{l}\text { Nominally } 0.1-3 \mu \mathrm{m} \text { (depends } \\
\text { on refractive index of aerosol) }\end{array}$ & $\begin{array}{l} \pm 20 \% \text { (diameter) } \\
\pm 15 \% \text { (concentration) }\end{array}$ \\
\hline $\begin{array}{l}\text { Dry aerosol light scattering co- } \\
\text { efficient at } 450,550,700 \mathrm{~nm}\end{array}$ & $\begin{array}{l}\text { TSI } 3563 \text { integrating } \\
\text { nephelometer }\end{array}$ & $\begin{array}{l}50 \% \text { cut-off efficiency at } \sim 3 \\
\mu \text { m diameter }(\mathrm{J} . \text { Trembath, } \\
\text { personal communication, 2012) }\end{array}$ & $\begin{array}{l}\sim 20 \% \text { (e.g. Johnson and } \\
\text { Osborne, 2011) } \\
\text { Detection limits } 0.1 \mathrm{Mm}^{-1} \text { for } \\
1 \text { min averages }\end{array}$ \\
\hline $\begin{array}{l}\text { Aerosol light absorption } \\
\text { coefficient at } 567 \mathrm{~nm} \text { (corrected } \\
\text { to } 550 \mathrm{~nm} \text { ) }\end{array}$ & $\begin{array}{l}\text { Particle soot absorption } \\
\text { photometer (PSAP) }\end{array}$ & As for dry nephelometer & $\begin{array}{l}\text { Variable but } \sim 30 \% \text { (see Bond } \\
\text { et al., 1999) } \\
\text { Detection limit better than } 1 \\
\mathrm{Mm}^{-1} \text { for } 1 \text { min averages }\end{array}$ \\
\hline
\end{tabular}

Before describing the individual instruments, it is important to understand how air samples reach them, and what the impact of the sampling method might be on the quantities measured. All the in-aircraft aerosol instruments (nephelometer, Particle Soot Absorption Photometer (PSAP), Aerodyne time-of-flight aerosol mass spectrometer (ToF-AMS) and Single particle Soot Photometer (SP2)) sample through Rosemount inlets. The nephelometers and PSAP sample through a common inlet, the ToF-AMS samples through an additional inlet closeby, whilst the SP2 samples through a third Rosemount in a similar position but on the other side of the aircraft. Particle loss can therefore occur both as a result of the inlet and the piping between the inlet and the instrument. The inlets have been fully characterised only recently and this confirms that the particle transmission upper limit is in the region 3.25 to 3.75 micron (J. Trembath, personal communication, 2011 and Ryder et al., 2012). As the maximum size of particle sampled by the ToF-AMS and SP2 is smaller than this (discussed below), these instruments are not limited by the inlets. Furthermore, the sizes for which scattering and absorption are constrained by the inlests are consistent with the sizes measured by the wing-borne Particle Measuring System Passive Cavity Aerosol Spectrometer Probe 100-X (PCASP) - this is important for the closure experiments discussed in Sect. 5. During the characterisation experiments, there was also found to be some enhancement of aerosol by the inlets (J. Trembath, personal communication, 2012 and Ryder et al., 2012). Below around $0.7 \mu \mathrm{m}$ the enhancement is around 1.5 times and similar for both the
AMS and nephelometer/PSAP inlets (the SP2 inlet was not included in this comparison). At larger sizes the enhancement varied between inlets, but this is of less relevance to the aerosol measured in this study.

Aerosol scattering coefficients at 440, 550 and $700 \mathrm{~nm}$ are measured using a TSI 3563 nephelometer. The resulting scattering is corrected for angular truncation, temperature and pressure as according to Anderson and Ogren (1999) and Turnbull (2010). It is assumed to be applicable to "dry" aerosol, although the sample was not actively dried during these flights. The sample is certainly at lower than ambient relative humidity due to the effect of heat from the nephelometer electronics and lamp, the dynamic heating through deceleration of the input flow which reaches the instrument and the increased temperature of the sample lines compared to ambient air. However, the sample humidity depends on the ambient relative humidity and when this is high the sample may not be absolutely dry. During EUCAARI-LONGREX, a second TSI 3563 nephelometer, the "wet-neph" was operated in series with the standard nephelometer (e.g. Haywood et al., 2008). The sample flow through this nephelometer is humidified to a set value between 45 and $95 \%$. During an SLR, the humidity is either cycled through a range between these values, or set at a fixed high level. The value $f(\mathrm{RH})$ is defined as the ratio of scattering coefficient measured in the wet-neph to the scattering coefficient measured by the original nephelometer. To minimise the uncertainty due to the unknown RH of the sample in the dry nephelometer, only sections of SLR where the relative humidity measured in the 
dry nephelometer is less than $30 \%$ are used to estimate the growth factors for scattering. For situations when the standard nephelometer recorded humidities higher than $30 \%$, the growth curve for dry sections of the same flight have been used to adjust the standard scattering coefficient to values at $20 \%$ and these are reported as "dry" scattering coefficients.

The aerosol absorption coefficient at $567 \mathrm{~nm}$ is measured using a Radiance Research Particle Soot Absorption Photometer (PSAP). The air is sampled through the same inlet as is used by the nephelometer, and measurements are also therefore assumed to be representative of aerosol below $30 \%$ relative humidity. The raw data is corrected for pressure and flow rate and for spot size effects as described by Bond et al. (1999), Ogren (2010) and Turnbull (2010). The absorption at $550 \mathrm{~nm}$ is found assuming an inverse dependence of absorption with angstrom exponent (e.g. Bond and Bergstrom, 2006).

The aerosol number size distribution is measured using a Particle Measuring System Passive Cavity Aerosol Spectrometer Probe 100-X(PCASP) mounted in a wing-pod. This provides aerosol sized in 15 bins ranging from approximately 0.1 to 3 micron diameter. The bin widths had previously been calibrated in laboratory experiments. In this study we have not adjusted the bin widths for the refractive index as the difference from calibration standards was small.

The total non-refractory mass is measured by an Aerodyne time-of-flight aerosol mass spectrometer (ToF-AMS) and reported as the mass of groups of chemical composition (e.g. organics, nitrate, sulphate, ammonium and chloride). Only particles less than approximately $800 \mathrm{~nm}$ aerodynamic diameter are sampled by the instrument. However, the sub-micron mass captured by the AMS agreed within 30\% (campaign average) with the volume convolved number size distribution from the PCASP (Morgan et al., 2010a using densities from Cross et al., 2007) which suggests that the majority of the sub-micron mass is captured by the AMS.

The mass of sub-micron refractory black carbon is measured via incandescence of individual particles by the Single particle Soot Photometer (SP2). This instrument is described in detail in Schwarz et al. (2006) and in the context of this measurement campaign and platform by McMeeking et al. (2010). The SP2 captured between $80-100 \%$ of the submicron $\mathrm{BC}$ mass based on log-normal fits to the measured size distribution (McMeeking et al., 2010). We did not apply a correction factor to account for the non-detected mass, as has been done in previous studies involving the SP2 (e.g. Schwarz et al., 2008) but rather report the mass observed within the instrument's detection range (i.e. sub $800 \mathrm{~nm}$ ).

Optical properties were then derived as follows.

\subsubsection{Specific mass extinction coefficient at $0.55 \mu \mathrm{m}$}

The mass-specific extinction coefficient $\left(k_{\mathrm{e}}\right.$, units $\mathrm{m}^{-2} \mathrm{~g}^{-1}$ ) can be determined by considering the relationship between the total mass of aerosol measured by the ToF-AMS and
SP2 instruments and the measured extinction from the nephelometer and PSAP. Uncertainty in the measured extinction has been calculated from uncertainties in scattering and absorption as measured by the nephelometer and PSAP instruments respectively. Here we have estimated the measurement uncertainty in scattering as $20 \%$ and in the absorption as $30 \%$ (Bond et al., 1999; Weingartner et al., 2003; Virkkula et al., 2005). Uncertainty in the SLR-averaged quantities used here also derive from variability experienced during the $15 \mathrm{~min}$ SLRs. The average in-run variability of scattering from the nephelometer ranged from $12 \%$ for B 370 to $34 \%$ for B364. For the PSAP absorption measurements, the in-run variability was generally considerably higher, ranging from $16 \%$ for B368 to $48 \%$ for B365. Combining these sources of uncertainty results in an average error of around $30 \%$ in the measured scattering and $50 \%$ in measured absorption. The uncertainty in extinction (25\%) is closer to that in scattering since the absorption is only a small component for this aerosol. Schmid et al. (2006) found that airborne nephelometer and PSAP measurements tended to give extinction values that are biased low compared to airborne sunphotometers and that remote sensing measurements tended to give higher values than in-situ ones. Systematic errors in extinction coefficient were $15-20 \%$ at visible wavelengths with random errors from $26 \%$ to $98 \%$. Our error estimates for extinction are not inconsistent with these findings.

\subsubsection{Single scattering albedo (SSA) at $0.55 \mu \mathrm{m}$}

The single scattering albedo (SSA) is defined as the ratio of scattering to the total extinction of radiation by the aerosol defined for a particular wavelength. The wavelength of $0.55 \mu \mathrm{m}$ is widely used in aerosol studies since it is near the peak of the visible solar radiation spectrum. Additionally the degree of scattering of radiation is strongest at a wavelength comparable to its radius. Most atmospheric aerosols, with the possible exceptions of mineral dust, some volcanic ash and sea salt, have volume distributions peaking below $1 \mu \mathrm{m}$, therefore $0.55 \mu \mathrm{m}$ captures representative optical effects.

The nephelometer and PSAP measurements are combined with consideration of RH effects to calculate the "dry" single scattering albedo $\left(\omega_{\mathrm{dry}}\right)$ at $0.55 \mu \mathrm{m}$. This is calculated for all straight and level runs (SLR) for each of the flights. Using the estimated uncertainties in measured extinction and scattering results in around a $40 \%$ uncertainty in SSA. In Sect. 4, the "ambient" single-scattering albedo $\omega_{\text {amb }}$ is calculated using the non-humidified nephelometer and the growth factor derived from the humidified nephelometer.

\subsubsection{Aerosol optical depth}

The aerosol optical depths (AODs) are retrieved by integrating the extinction profile, generally taken as the sum of the aerosol scattering and aerosol absorption. Because of 
problems with the PSAP instrument pressure regulation during the campaign, many segments of the aircraft ascents and particularly descents were not usable. Thus, for AOD calculations, only the scattering coefficient profiles were integrated. The error introduced by neglecting absorption is modest in this campaign since the PSAP values are always less than $10 \%$ of the nephelometer values (see Sect. 3.2). Some profiles cover a restricted altitude range (in particular, aerosol near the ground is not likely to have been measured) and this can lead to the AOD calculated in this study being a lower bound. It is also important to remember that since the profiles are performed in an aircraft having a finite ascent and descent rate, the aircraft may cover a few hundred kilometers in the horizontal during each profile, depending on the flight pattern. If there is substantial horizontal variability in aerosol profile, this can lead to potentially unrealistic averaging of the aerosol. Assuming that the horizontal variability experienced during profiles is similar to that observed during 15 min SLR runs, the uncertainty in scattering is around $30 \%$ and this results in an uncertainty of $30 \%$ in optical depth estimated by this method.

\subsection{Scattering code}

A Mie scattering code as released alongside the Edwards and Slingo (1996) radiative transfer code is used to calculate absorption and scattering from the SLR mean refractive indices and size distributions for each run and each flight. The aerosol is assumed to be internally mixed, and volume weighting of refractive indices is used to produce a refractive index for the aerosol mixture. The PCASP is an optical particle counter. Each individual particle that enters the instrument is exposed to a laser beam and produces a scattered peak. The height and width of this peak is recorded, and the signal is binned based on the peak height. The inversion of scattering peak to size uses a calibration curve derived from Mie theory for calibrated spheres of known size and known refractive index. Very recent work by Rosenberg et al. (2012) demonstrates that the bin edges can differ by an average of $13 \%$ and up to $30 \%$ from that provided by the manufacturer due to both systematic changes and the effect of differing refractive index of ambient aerosol compared to the calibration standards. The PCASP was calibrated in the laboratory on return from EUCAARI and bin widths used here are based on that calibration, however the refractive index used was of the calibration standard rather than that of the ambient aerosol. The refractive index correction becomes more important for aerosol with significant absorption. Based on the low mass of BC observed in this aerosol, we anticipate that our uncertainty in the size is less than $30 \%$. Using a change in $13 \%$ of bin sizes on a limited number of runs, changes seen in modelled scattering were less than $5 \%$ and changes in absorption a maximum of $10 \%$. These uncertainties are smaller than both the uncertainty in measured scattering and absorption due to variability within a SLR, and the estimated measurement uncertainty of both the PSAP and the nephelometer.

\section{Results: measured optical properties}

In this section, the nephelometer, PSAP, ToF-AMS, SP2 and PCASP data are used as described in Sect. 2.2 to describe the radiatively relevant properties of dry aerosols across northwest Europe during EUCAARI-LONGREX.

\subsection{Mass extinction co-efficient}

Figure 2 shows the total extinction (sum of scattering from nephelometer and PSAP) as a function of total mass of submicron aerosol (combined from AMS and SP2). The extinction is dominated by scattering. The campaign mean mass extinction co-efficient for dry aerosol (given by the slope of the best fit line in Fig. 2) is $4.4 \pm 0.2 \mathrm{~m}^{2} \mathrm{~g}^{-1}$ (at $550 \mathrm{~nm}$ ) - the uncertainty here is derived from the average residual from the best line fit shown in Fig. 2. The estimated errors in extinction as derived from the measurements and described in Sect. 2 are also shown and range between 20 and $30 \%$ for the majority of the flights. Morgan et al. (2010b) report the scattering co-efficient of ambient aerosol derived using a similar analysis for flights B366 and B379 to be $4.94 \mathrm{~m}^{2} \mathrm{~g}^{-1}$ (no uncertainty is given). These values are consistent with our dry value since these flights were close to Cabauw with relatively high nitrate (aircraft measured $2-12 \mu \mathrm{g} \mathrm{sm}^{-3}$ for B366 and $>6 \mu \mathrm{g} \mathrm{sm}^{-3}$ for B379) and since the scattering coefficient would be expected to increase with relative humidity. Bates et al. (2006) give a somewhat lower value for submicron aerosol sulphate/carbonaceous aerosol over the N. Atlantic of $3.66 \mathrm{~m}^{2} \mathrm{~g}^{-1}$. Again this value is consistent with that found here since there is a larger proportion of ammonium nitrate in much of the north-west European aerosol (approximately 0.26 mass fraction in Morgan et al. (2010a) compared with less than 0.1 in Bates et al. (2006) and ammonium nitrate is highly scattering. Density differences between the components can also play a role. The ADRIEX campaign in Northern Italy using the same measurement platform (but a different methodology and some different instrumentation) found a value of $3.5 \pm 1.2 \mathrm{~m}^{2} \mathrm{~g}^{-1}$ for ambient industrial aerosol with a large nitrate component but a higher organic mass fraction (Osborne et al., 2007); again this is consistent with our value within the measurement uncertainties.

Figure 2 also shows a clear increase in extinction during the LONGREX-2 period (flight B368 in "fresh" aerosol to flight B374 in "aged aerosol"). However there is little to distinguish the three different LONGREX periods from each other.

\subsection{Single scattering albedo (SSA)}

Figure 3 shows the measured single scattering albedo (dry aerosol) across Europe as defined by the mean during each 


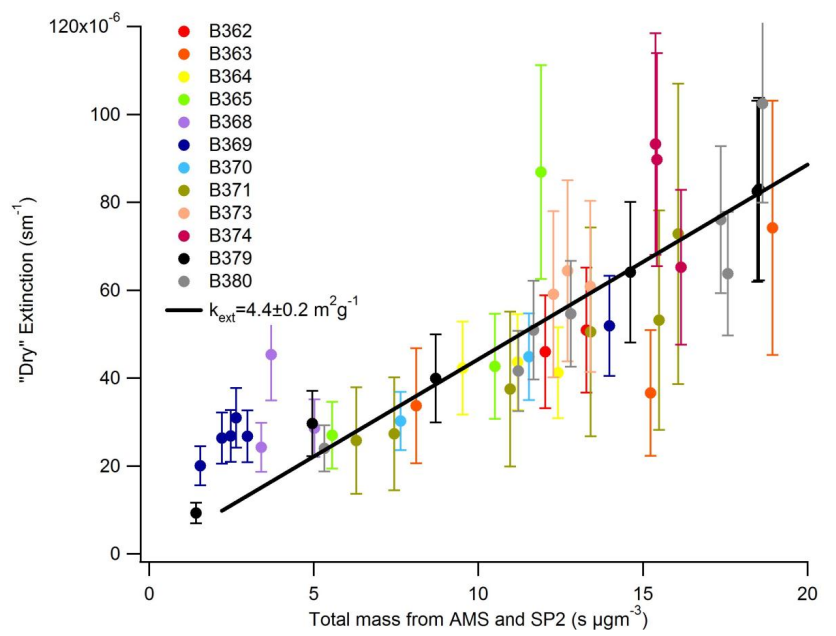

Fig. 2. Aerosol extinction at $550 \mathrm{~nm}$ as calculated as the total of scattering measured by the nephelometer and absorption measured by PSAP as a function of total aerosol mass (from total of Aerosol Mass Spectrometer and SP2 instrument). Error bars are uncertainty as calculated from measurement errors and in-run variability of scattering and absorption (one standard deviation) for each individual run. Solid line represents a mass extinction relationship of $4.4 \pm 0.2 \mathrm{~m}^{2} \mathrm{~g}^{-1}$ (uncertainty is the average residual from the bestfit line). All quantities reported at standard temperature and Pressure (STP).

SLR. It is clear from Fig. 3a that the SSA for dry aerosol across NW Europe is relatively high, generally exceeding 0.93 . Values of 0.9 and lower are generally restricted to regions very close to fresh sources. The highest values are seen in flights over the North Sea and west of Ireland. Flight and campaign average SSA is shown in Table 3 for two regions of vertical profiles, "LOWLEV" - below $250 \mathrm{~m}$ and "BL" boundary layer between $250 \mathrm{~m}$ and $2000 \mathrm{~m}$. Above this altitude, aerosol amounts were generally low and hence large uncertainties are introduced in the nephelometer and PSAP measurements. BL values for dry aerosol range from 0.92 to 0.94 with the exception of one flight (B368) which shows a much smaller SSA of 0.7. This flight was in a very different location to all the others, being in the eastern Baltic Sea. Local pollution sources are likely to be different there, although the absolute mass loading of $\mathrm{BC}$ was the smallest observed. These values must therefore be treated with some caution. The "LOWLEV" runs for B362, B365, B369 and B74 all show a considerably higher SSA than the BL runs for the same flights. All these low level runs were over water, and the presence of sea salt might explain the higher dry SSA. The ToF-AMS measurements also show enhanced ammonium nitrate in moist layers close to the sea surface and this would also contribute to a higher SSA. In contrast, the low level SSA for B380 is lower than the BL value. This run was completed just off the south coast of the UK and the ToF-AMS and SP2 data shows relatively high amounts of sulphates, or-

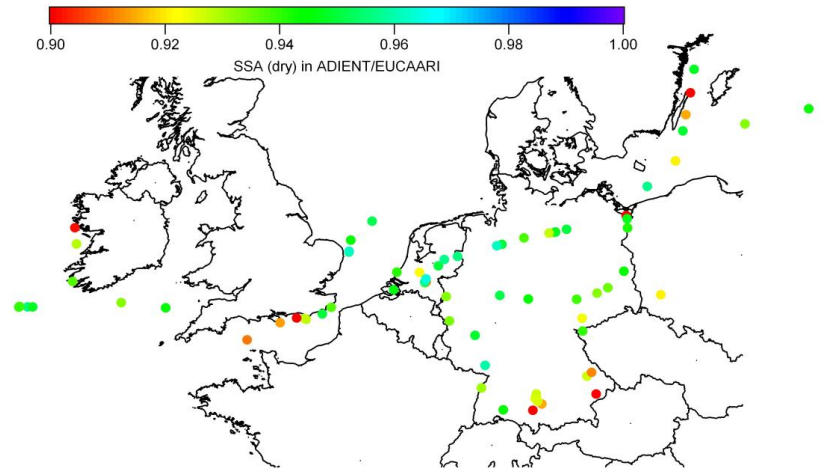

Fig. 3. Single scattering albedo (SSA) of dry aerosol at $550 \mathrm{~nm}$ as derived from PSAP and nephelometer measurements on board the BAe146. Markers are positioned at the mid-points of the SLRs. Only SLRs below $2000 \mathrm{~m}$ (i.e. within the average boundary layer) are included as the aerosol concentrations drop rapidly above the boundary layer leading to large uncertainties in the scattering and absorption measurements.

ganics and $\mathrm{BC}$ and relatively little highly scattering nitrate, suggesting a local pollution source and consistent with a low SSA.

The campaign average SSA derived from the SLR averages shown in Table 3 (excluding B368) is $0.93 \pm 0.03$. The relatively high value reflects the large proportion of scattering material (sulphate, nitrate and organics) in EU anthropogenically influenced aerosol. The uncertainty range is similar to that quoted in other studies. During LONGREX-2 (1014 May, flights B369-B374, following Morgan et al., 2010a) the flow is essentially from north east to south west following the air mass circulating around the southern side of the anticyclone and therefore sampling progressively aged aerosol from flight B369-B374. When SSA is plotted as a function of longitude (not shown), and considering the uncertainty in SSA, no immediate relationship with longitude is apparent. Increased SSA is however found preferentially in regions of increased nitrate, these being generally to the west of the domain and also over Belgium and the Netherlands where there are strong emissions of nitrate pre-cursors. This dependency of SSA on nitrate mass has also been observed within the context of a single flight (Morgan et al., 2010a). These findings have important implications for the calculations of radiative forcing since nitrate has yet to be included in many aerosol transport models and GCM aerosol schemes.

It is perhaps surprising that the $\mathrm{BC}$ contribution to total aerosol mass is so low, even for a rather polluted air mass. However, the BC mass fraction is similar to that found in the polluted Po Valley using methodology similar to Fiebig et al. (2002) and others (Cook et al., 2007). Compared to ground based measurements from EUCAARI, the FAAM $\mathrm{BC}$ measurements appear slightly low, and it is also true that the BAe-146 on most flights did not sample the atmospheric 
Table 3. Flight averaged SSA values for aerosol derived from PSAP and nephelometer for dry and ambient (scattering corrected for relative humidity measured during run) aerosol. LOWLEV is mean of SLRs below $250 \mathrm{~m}, \mathrm{BL}$ is mean of all SLRs between $250 \mathrm{~m}$ and $2000 \mathrm{~m}$, Numbers in brackets in the dry columns describe number of runs used to calculate the mean in each case. Where there is no entry in the table, no runs were made in that height region.

\begin{tabular}{lrr|rr}
\hline \multirow{2}{*}{ Flight number } & \multicolumn{2}{c|}{ LOWLEV } & \multicolumn{2}{c}{ BL } \\
\cline { 2 - 5 } & DRY & AMBIENT & DRY & AMBIENT \\
\hline B362 & $0.96(1)$ & 0.97 & $0.94(10)$ & 0.95 \\
B363 & & & $0.94(5)$ & 0.95 \\
B364 & & & $0.93(4)$ & 0.94 \\
B365 & $0.96(1)$ & 0.96 & $0.91(6)$ & 0.93 \\
B366 & & & $0.93(6)$ & 0.94 \\
B367 & & & $0.92(2)$ & 0.92 \\
B368 & & & $0.70(6)$ & 0.72 \\
B369 & $0.93(2)$ & 0.94 & $0.92(4)$ & 0.92 \\
B370 & & & $0.94(4)$ & 0.95 \\
B371 & & & $0.92(6)$ & 0.94 \\
B373 & & & $0.93(8)$ & 0.93 \\
B374 & $0.94(2)$ & 0.96 & $0.93(3)$ & 0.94 \\
B379 & & & $0.94(5)$ & 0.95 \\
B380 & $0.90(1)$ & 0.90 & $0.94(6)$ & 0.95 \\
\hline MEAN & $\mathbf{0 . 9 4}$ & $\mathbf{0 . 9 4}$ & $\mathbf{0 . 9 1}$ & $\mathbf{0 . 9 2}$ \\
(ex B368) & $\mathbf{0 . 9 4}$ & $\mathbf{0 . 9 4}$ & $\mathbf{0 . 9 3} \pm \mathbf{0 . 0 3}$ & $\mathbf{0 . 9 4} \pm \mathbf{0 . 0 3}$ \\
\hline
\end{tabular}

regions which were predicted by transport models to contain the peak BC amounts (Hamburger et al., 2011).

\subsection{Vertical profile and optical depth}

Figure $4 \mathrm{a}$ shows the variation of dry AOD derived as described in Sect. 2.2.3. The values estimated for the most complete profiles used are shown in Table 4 . There is clearly a general increase in dry AOD from north east to south west across the EUCAARI flight region. The flights to the north and Baltic sea area represent relatively light loadings in a clean air mass before the anticyclonic flow sweeps the air mass south and predominantly eastwards, collecting emissions from north western Europe. Highest AOD values are to be found in the region of Cabauw, heavily influenced by local and cumulative emissions and secondary aerosol formation, including a lot of nitrate which scatters strongly, and to the west of Ireland in the most aged sample, which has again been influenced heavily by emissions contributing to nitrate formation over the UK. Many of the profiles taken over land are incomplete due to restrictions on the minimum altitude permissible for the aircraft; their lower limit being at $500 \mathrm{~m}$ or even higher. Thus the AOD estimated here represents in general a lower limit.

Typical vertical profiles encountered are shown in Fig. 5 (here the scattering by dry aerosol is in red, whilst the blue traces show the enhanced scattering when relative humidity is taken into consideration - see Sect. 4). Profiles of number concentration from the PCASP and $\mathrm{CO}$ mixing ratio are
Table 4. Optical depths at $550 \mathrm{~nm}$ calculated from the most complete scattering profiles for dry and ambient aerosol (scattering corrected using the measured growth factor).

\begin{tabular}{lllll}
\hline Flight & Profile & $\begin{array}{l}\text { Approximate } \\
\text { Altitude Range }(\mathrm{m})\end{array}$ & $\begin{array}{l}\text { AOD } \\
\text { (dry) }\end{array}$ & $\begin{array}{l}\text { AOD } \\
\text { (ambient) }\end{array}$ \\
\hline B362 & P8 & $0-3048$ & 0.082 & 0.106 \\
& P9/P10 & $0-3048$ & 0.076 & 0.092 \\
B365 & P6 & $1000-8000$ & 0.120 & 0.169 \\
& P7/P8 & $500-3700$ & 0.054 & 0.083 \\
B370 & P4.2 & $700-3500$ & 0.072 & 0.083 \\
B372 & P16 & $400-4500$ & 0.080 & 0.103 \\
B373 & P7 & $0-3000$ & 0.138 & 0.158 \\
B373 & P13 & $0-3300$ & 0.116 & 0.141 \\
B374 & P6 & $0-6000$ & 0.194 & 0.278 \\
& P12 & $0-7000$ & 0.168 & 0.212 \\
B379 & P5/P6/P7/P8 & $500-8500$ & 0.148 & 0.198 \\
\hline
\end{tabular}

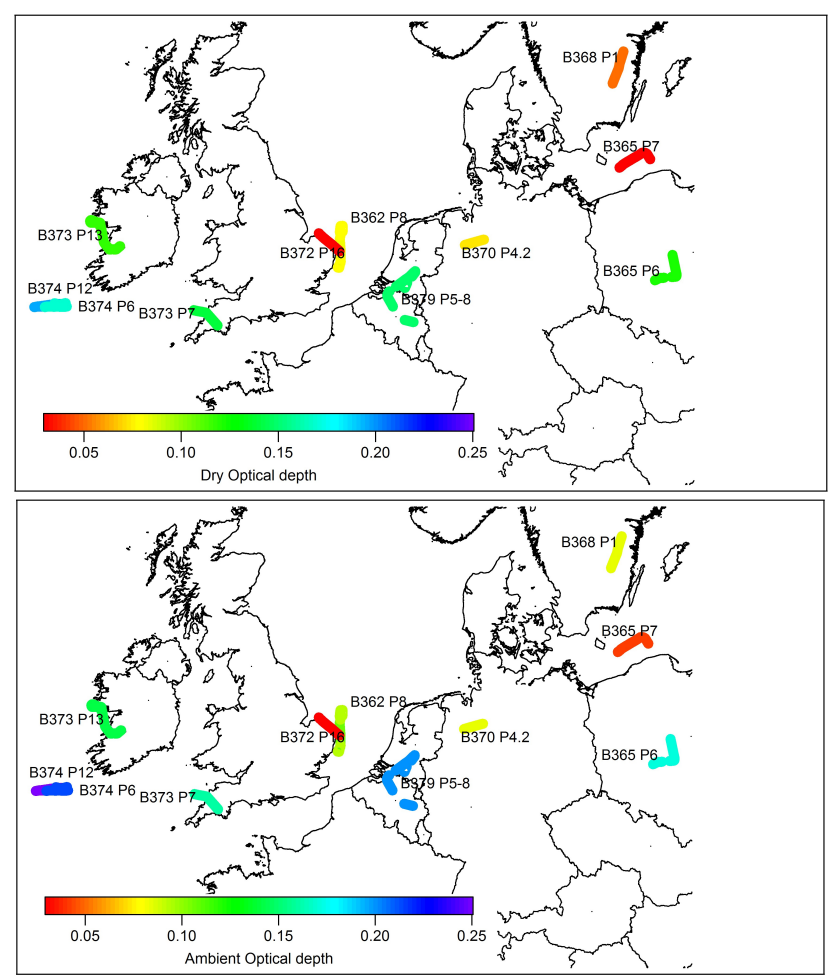

Fig. 4. (a) Dry aerosol optical depth at $550 \mathrm{~nm}$ and (b) ambient optical depth at $550 \mathrm{~nm}$ for deep profiles flown during EUCAARI.

also shown for context. The profiles in Fig. 5 represent the range of vertical structures encountered during EUCAARI (and their positions are marked in Fig. 4). Figrue 5a shows profile 8 of B362 (North Sea) and is typical of many profiles performed during the campaign, with the majority of aerosol being below $2000 \mathrm{~m}$ in the boundary layer and considerable structure within the BL itself. The structure in scattering is generally mirrored in both the PCASP number concentration and the $\mathrm{CO}$, although the $\mathrm{CO}$ profile suggests that the 


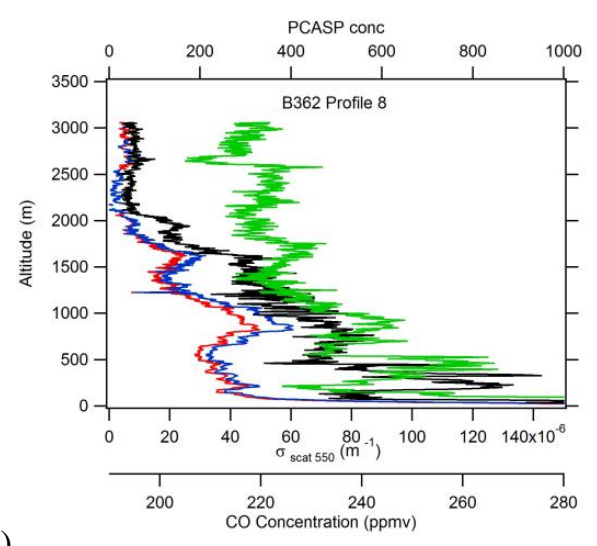

a)

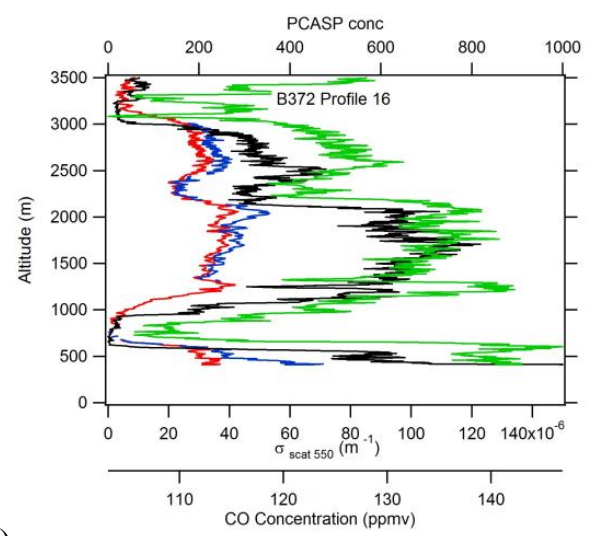

c)

d)

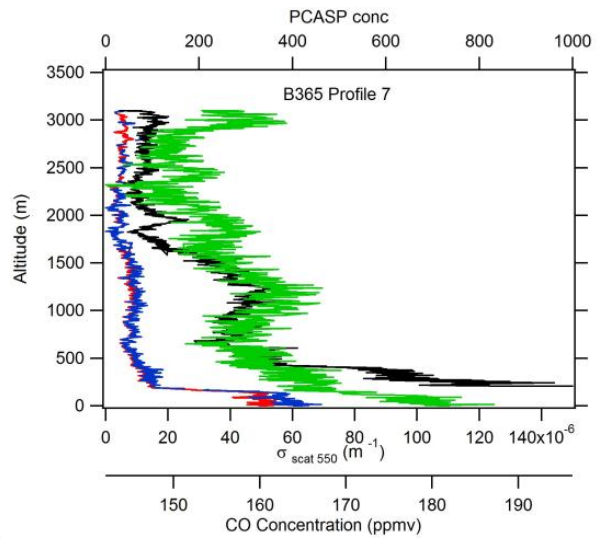

b)

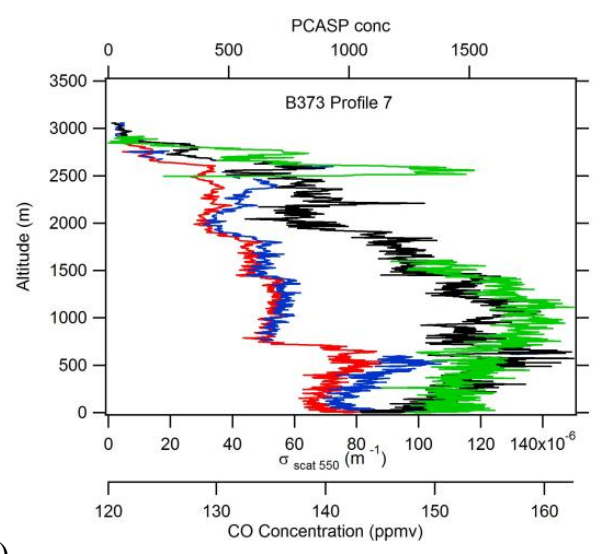

Fig. 5. Example profiles of scattering from the EUCAARI campaign. (a) Profile 8 from B362; (b) profile 7 from B365, (c) profile 16 from B372 and (d) profile 7 from B373. Dry aerosol scattering - red, scattering at ambient relative humidity - blue, PCASP number concentration in black and Carbon monoxide concentration in green. Scales for PCASP number concentration and CO concentration differ between panels.

boundary layer top is at a slightly higher altitude than do the aerosol measurements. The $\mathrm{CO}$ concentrations seen during this profile are higher than many of the other profiles. Morgan et al. (2010b) and Hamburger et al. (2011) give more detailed discussion of the causes of some of this vertical structure.

Figure $5 \mathrm{~b}$ shows a very clean profile encountered over the southern Baltic Sea in B365 where substantial aerosol scattering is only seen in the lowest layers - this is likely to be sea salt. The number concentration and $\mathrm{CO}$ do show a more prominent peak up to around $1500 \mathrm{~m}$, although the $\mathrm{CO}$ concentrations are much lower than seen in Fig. 5a. The lack of substantial scattering in the same levels perhaps points to an increase in aerosol that is relatively inefficient in scattering either due to size or composition - however, it is difficult to draw any firm conclusions from the data available.

Figure $5 \mathrm{c}$ shows an elevated layer of aerosol (in terms of number concentration and scattering), which is accompanied by an increase in $\mathrm{CO}$ encountered during profile 16 of B372 - this was observed in profiles off the eastern coast of the UK and the layering reflects local sources below $750 \mathrm{~m}$ and more aged continental European aerosol above. The number concentration and $\mathrm{CO}$ profiles are in fact indicative of two different layers between 750 and $2250 \mathrm{~m}$, and then between $2250-3000 \mathrm{~m}$ ). Figure $5 \mathrm{~d}$ shows a profile in aged pollution over the western Atlantic from B374. The peak in scattering at the top of the boundary layer (just below $2500 \mathrm{~m}$ ) is similar to that observed in Morgan et al. (2010b). That study demonstrated an increase in nitrate here, and the evidence from Fig. 5d suggest both a relative enhancement of aerosol number here, and specifically an increase in scattering due to relative humidity (the blue trace shows enhancement but the red trace does not). Again there is considerable structure throughout the profile below $3000 \mathrm{~m}$, probably corresponding to aerosols from both the UK and the more aged advected European aerosol above.

\section{Hygroscopic growth and impact on optical properties}

Aerosols are well known to interact with water in the atmosphere, a property which may influence their size, light scattering and chemical reactivity. When an aerosol is dominated 

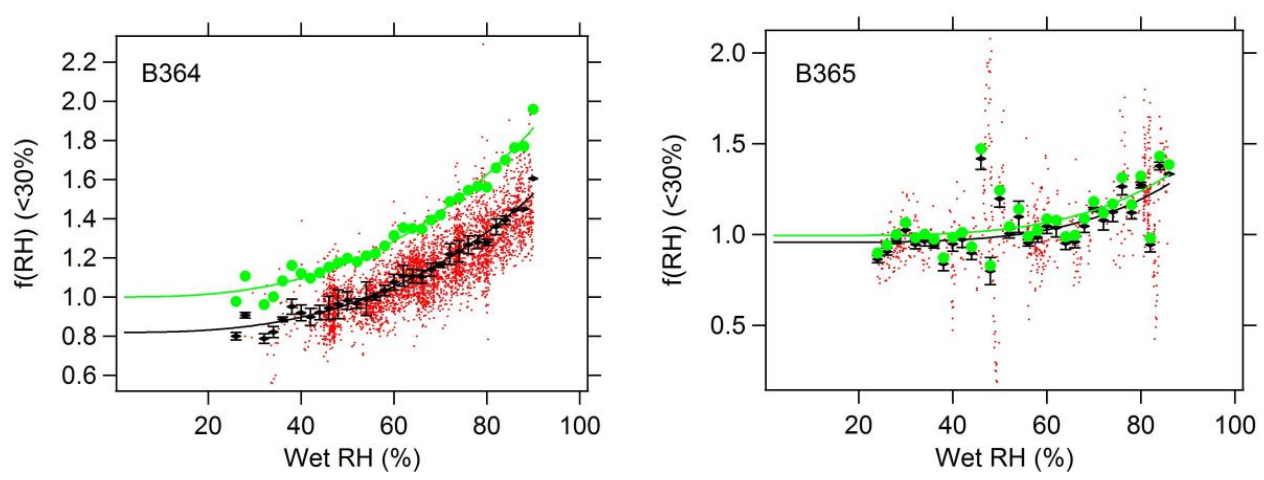

Fig. 6. Humidograms constructed using the wet nephelometer measurements for the entire flights of B364 (left-hand panel) and B365 (righthand panel), showing all data for which the dry nephelometer recorded less than $30 \%$ relative humidity (dots), 2 min averages with standard deviations (black diamonds and error bars) and the Model 2 fit to the 2 min average data (black line). Also shown by green dots is the 2 min average data rescaled to account for particle losses between the nephelometers, with the Model 2 fit to this scaled data (used for Fig. 7) shown as the green line.

by some chemical components, such as nitrate and sulphate, water is easily absorbed by the aerosol causing an increase in size and light scattering (Tang, 1996). Black carbon, on the other hand, is hydrophobic in its pure form and is generally understood to reduce the hygroscopicity of aerosol mixtures in which it is a significant component. The mixing state of the aerosol and the content of the individual chemical components are critical factors in influencing the hygroscopicity of the aerosol (McMeeking et al., 2011a; McFiggans et al., 2005; Gysel et al., 2007). Finally, the influence of organics on the water uptake of aerosol has been the subject of many studies and this relationship is still not well understood (e.g. Topping et al., 2005).

Mean humidograms, showing $f(\mathrm{RH})$ as a function of applied RH were taken from the wet nephelometer as described in Sect. 2.2 for each flight during EUCAARI and fit to an empirical model. In this study, Model 2 taken from Kotchenruther et al. (1999) provided acceptable fits to the data:

$\sigma_{\mathrm{s}}=\sigma_{\mathrm{s}, \mathrm{d}}\left(1+a\left[\frac{\mathrm{RH}}{100}\right]^{b}\right)$

where $\sigma_{\mathrm{s}, \mathrm{d}}, a$, and $b$ are fitting parameters to the data. As an example, the humidogram data for flight B364 and B365 are shown in Fig. 6. To ensure that the full increase in scattering due to hydration was measured, only data points registering less than $30 \%$ "dry" relative humidity were used. In Fig. 6, the raw data (dots) displays high variability due to small scale variations in $f(\mathrm{RH})$, at a constant $\mathrm{RH}$ value (likely an artefact) (Osborne et al., 2006). Thus, the data have been averaged into $2 \%$ mean $\mathrm{RH}$ bins. Particle loss between the dry neph and the wet neph is potentially responsible for the low bias in Fig. 6, such that $f(\mathrm{RH})$ does not equal 1 at low RH. Tests on a number of flights during EUCAARI suggest that this is a maximum $10 \%$ loss in scattering (K. Turnbull, personal communication, 2011). An alternative or additional possibility is that there is a problem with the zeroing of one or other nephelometer. A final consideration is that the original TSI sensors over-estimate RH by up to $15 \% \mathrm{RH}$ at high $\mathrm{RH}$ (Fierz-Schmidhauser et al., 2010). In order to produce Fig. 7, the binned wet neph data for which dry neph RH $<30 \%$ was fit to the Model 2 formulation of Kotchenruther et al. (1999). The degree to which this fit deviated from $f(\mathrm{RH})=1$ at $30 \%$ RH was assessed and used to scale the 2 min averages to account for particle loss between the nephelometers and any zero offset issues. These scaled points are shown in green in Fig. 6 for the two flights selected, along with the fit to the model (green line). In all cases except for B374, the scaling needed was less than $10 \%$ which is consistent with independent estimates of scattering loss estimated from time periods when the two nephelometers were measuring the same $\mathrm{RH}$. Therefore this approach is deemed valid.

The Model 2 fitted curves, corrected as described above for particle loss are shown for each flight in Fig. 7. Many of the flights show broadly similar growth curves. The range of growth curves is spanned by B374 which shows substantially enhanced growth rates, and B365 which shows reduced growth rates. Considering the meteorological situation and location of these flights, this behaviour most likely has a physical explanation - B365 is in relatively clean air over the Southern Baltic Sea - but pollution episodes there contain proportionally much less nitrate and more hydrophobic components than observed further west and this would result in a shallow growth rate curve. At the other extreme, B374 is the westernmost flight with aged aerosol containing high proportions of nitrates and sulphates - both of which are very hygroscopic. It is appropriate therefore that this growth curve shows most enhancement of scattering across a range of relative humidities. However, B374 also has the highest "dry" humidities and therefore the amount of data used to calculate $f(\mathrm{RH})$ is small, giving rise to considerable potential for error for this flight. The B367 curve is most markedly different in 


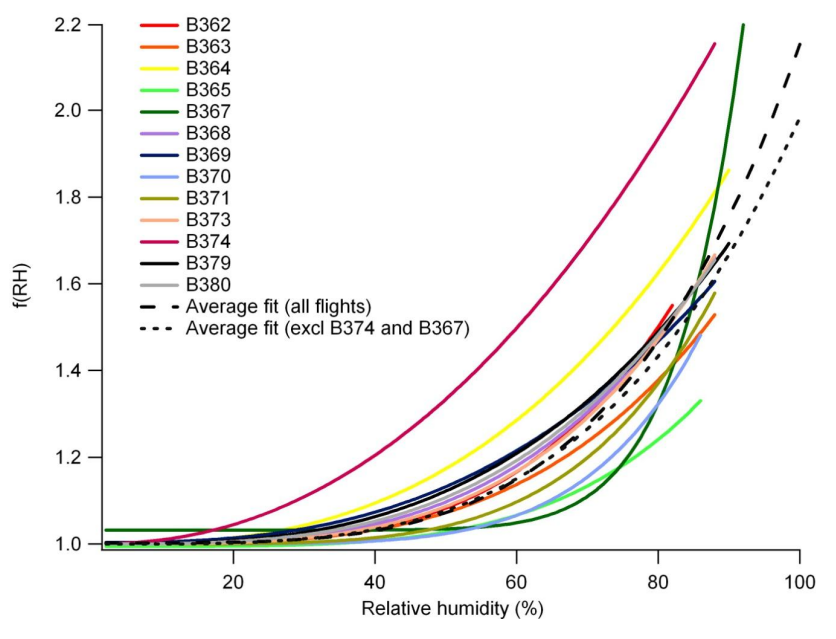

Fig. 7. Growth curves derived from the wet nephelometer and averaged over each flight. Solid dashed line - average fit calculated using all flights. Solid dotted line, average fit excluding B374 and B367.

its hygroscopic behaviour compared to all other flights - this was performed in a very different location (Southern Germany) to the other flights and this may be responsible for the different hygroscopicity curve.

Also shown in Fig. 7 is an average fit using all the individual curves (and an alternative removing the two "outliers" of B367 and B374. The differences between the average fits are small below around $90 \% \mathrm{RH}$ and therefore similar under the RH conditions (less than $70 \%$ ) experienced during most of the EUCAARI flights. Given the similarity of the flight average curves and the variability within given flights, an average hygroscopicity curve was taken for the entire campaign ( $a=1.1475, b=4.0399)$. The average curve exhibits modest water uptake, with an $f(\mathrm{RH})$ value of 1.5 at $80 \%$ $\mathrm{RH}$. This hygroscopic growth is comparable to other humidograms published in the literature from the UK and European anthropogenic aerosol studies (Haywood et al., 2008).

The impact of relative humidity on optical properties can be seen by increasing the scattering component from the nephelometer by the growth factor indicated from the wet nephelometer campaign average. We assume no influence of humidity on absorption. Redemann et al. (2001) suggest that absorption can be enhanced by up to $20 \%$ at $80 \% \mathrm{RH}$ and by as much as $35 \%$ at $95 \% \mathrm{RH}$, but $\mathrm{RH}$ experienced during these flights was generally less than $70 \%$ so the effect is likely to be smaller than $20 \%$. Including the relative humidity effect results in the campaign mean extinction coefficient being increased by $13 \%$ reaching $5.6 \pm 0.3 \mathrm{~m}^{2} \mathrm{~g}^{-1}$. (Note that here the mass extinction coefficient is calculated per unit mass of dry aerosol, therefore the value increases on including the effect of relative humidity. If it were defined per unit mass of aerosol including the mass of water it would decrease.)
The ambient SSA is calculated by increasing the scattering value by the growth factor calculated using the wet nephelometer and assuming that the absorption is unaffected by growth due to the relative humidity. Redemann et al. (2001) suggested this assumption led to an overestimate of ambient SSA of up to 0.05 for a narrow size distribution of small particles. There is currently no way to measure this effect on board the BAe-146, but the average RH for the majority of the runs considered here was below $70 \%$ and therefore the effect is likely to be smaller in this study. The ambient SSA and AODs are shown alongside their dry counterparts in Tables 3 and 4 respectively. Generally the influence on SSA is quite small (differences in the average SSA compared to dry value being well within the uncertainty bounds on either quantity). This is due to the relative humidity being generally below $70 \%$. Figures 6 and 7 show that at this relative humidity the growth of the aerosol is relatively modest and therefore we would not expect dramatic increases in scattering or SSA.

However, for SLRs flown at low level over water (B362 over the North Sea, B365 in southern Baltic Sea and B374 over the Atlantic) a slightly stronger increase in SSA from the dry value is seen. Upon close examination, the low altitude runs over sea in B362, B365 and B374 correspond to the extreme outliers in Fig. 2 with a considerably elevated mass extinction efficiency (dry and ambient) when compared to other SLRs. In the case of B362 and B365, the nitrate mass fraction increases dramatically. For B362 over the North sea the total mass also increases dramatically, whilst for B365 over the southern Baltic, the total mass increase is more modest. Since nitrate aerosol is both highly scattering and highly hygroscopic we might expect both an elevated mass extinction efficiency and an enhanced difference between dry and ambient aerosol optical properties, as is shown in our results. In the case of B374, the departure from the line of best fit is less extreme and although the mass increases somewhat compared to the other runs, it is the organic fraction that increases rather than the nitrate component. As organics are both less scattering and less hygroscopic than nitrates, this is perhaps why the departure is less extreme in this case.

Figure $4 \mathrm{~b}$ shows the ambient AOD alongside the dry counterparts with the numerical values given in Table 4 . The ratio of ambient to dry AOD is largely determined by the average growth factor curve since scattering is dominant in all profiles and ranges from 1.15 (B373 P7 and B370 P4.2) to 1.43 (B374 P6) suggesting in most profiles a modest increase in aerosol optical depth due to relative humidity. However, the effect on AOD is more marked than that on SSA. It would be desirable to compare AOD estimates with those measured from the ground by the AERONET network. Unfortunately in most cases this is not possible since the match to an AERONET station was poor either due to a spatial or airmass difference. The most suitable match, B379 and the Cabauw station showed that the AOD measured from AERONET was 0.26 whilst the combination of scattering 
Table 5. Refractive indices and densities used for aerosol components in calculation of mixture density and refractive index for input to Mie calculations.

\begin{tabular}{|c|c|c|c|}
\hline Component & $\begin{array}{l}\text { Refractive } \\
\text { indices at } 550 \mathrm{~nm}\end{array}$ & $\begin{array}{l}\text { Density } \\
\left(\mathrm{g} \mathrm{cm}^{-3}\right)\end{array}$ & References \\
\hline Ammonium Sulfate $\left(\mathrm{NH}_{4}\right)_{2} \mathrm{SO}_{4}$ & $1.53-0 i$ & 1.77 & Toon (1976) \\
\hline Organic carbon (Swannee River Fulvic Acid) & $1.538-0.02 i$ & 1.5 & Dinar et al. (2008) Dinar et al. (2006) \\
\hline Black carbon & $1.95-0.79 i$ & 1.80 & Bond and Bergstrom (2006) \\
\hline Ammonium nitrate $\left(\mathrm{NH}_{4} \mathrm{NO}_{3}\right)$ & $1.611-0 i$ & 1.80 & Weast (1985) as cited in Cook et al. (2004) \\
\hline
\end{tabular}

profiles from the aircraft between $500-8500 \mathrm{~m}$ gave an AOD of 0.198. A slight underestimate might be expected because the method used here neglects the absorption optical depth. An alternative method is to use an average single scattering albedo to estimate the contribution to the AOD from absorption. Using the boundary layer SLR average single scattering albedo we can estimate that the true AOD should be between 3 and $9 \%$ higher than that calculated from the scattering profile alone. For B368 which has a very low SSA, if this is realistic, the total AOD would be $40 \%$ higher than that from the scattering alone. This is in addition to the uncertainty in AOD of $30 \%$ due to the uncertainty in the scattering measurements and combining these uncertainties would bring the aircraft value into better agreement with the ground based measurements. There may be an additional underestimate due to not sampling the lowest $500 \mathrm{~m}$ with the aircraft. Finally, Schmid et al. (2006) found that remote sensing measurements tended to give higher extinction values than in-situ measurements, again consistent with our airborne measurements under-estimating AERONET measurements.

\section{Scattering and absorption closure}

The scattering and absorption by aerosol mixtures can be calculated using scattering code if the refractive indices and size distribution are known. The refractive indices depend on the composition of the aerosol, and, if wet, the relative humidity. The ToF-AMS and SP2 instruments on board the FAAM can be used to determine the composition of the aerosol. For this paper, the mass loading of sulphates, organics, nitrates, and black carbon have been used together with volume weighted mixing rules to determine the refractive indices of an internally mixed aerosol having the size distribution measured by the PCASP. Initially we discuss the dry aerosol, since the nephelometer and PSAP instruments with which we can perform closure are thought to measure scattering and absorption of dry aerosol (rather than ambient). The assumption of an internally mixed aerosol is valid since in most cases the pollution encountered is aged to some extent (e.g. Moffet and Prather, 2009). We have assumed refractive indices and densities of the aerosol components as specified in Table 5 (the sensitivity of results to these assumptions is discussed below). Average size distributions as measured by the
PCASP for each SLR have been used with these refractive indices and Mie code which assumes a spherical homogenous droplet. The spherical assumption is appropriate for mixed anthropogenic aerosol, particularly in moderately humid environments; the homogenous droplet assumption may be less appropriate if there is a large mass of black carbon, whereby a coated shell approximation might be more useful. However, in most cases considered here, the black carbon mass fraction is small compared to the other components (being between 0.5 and $3 \%$ of total submicron aerosol mass, McMeeking et al., 2010). Therefore we consider only the homogenous case.

Figure 8 shows the results of closure studies for scattering (Fig. 8a) and absorption (Fig. 8b). For aerosol scattering, there is remarkably good agreement across all flights with the modelled scattering being within $30 \%$ of the $1: 1$ relationship - given that the estimated uncertainty in SLR mean scattering is $30 \%$, this is the best agreement we could envisage. (Note that uncertainty also exists in the calculated scattering due to uncertainty in refractive index, size distribution etc., however quantifying this is beyond the scope of this study). There is a slight bias evident with the modelled value slightly underestimating the measured scattering by around $15 \%$. Such a bias could be due to several factors. Firstly, if the aerosol being sampled by the nephelometer is not completely dry then the scattering would be slightly increased, however we have tried to correct for that effect in the measurements as described in Sect. 2.2.2. Secondly it is possible that the mass of one or more scattering components is underestimated by the ToF-AMS. Thirdly, there is uncertainty in the refractive indices, particularly that for black carbon and organic matter. However, tests varying the refractive indices of black carbon within the range suggested by previous studies have negligible impact on the scattering (not shown) and in any case, the bias is small in relation to uncertainties in nephelometer measurements. Finally, the ToF-AMS and SP2 both measure sub $0.8 \mu \mathrm{m}$ particles, whilst the scattering and absorption measured by the nephelometer and PSAP are produced by a larger range of particle sizes. This mismatch might be expected to lead to a lower modelled scattering than is measured, however, the magnitude of the bias is likely to be of similar order to the in-SLR variabililty.

The modelled absorption overestimates the measured absorption for the majority of runs and flights. Whilst the 

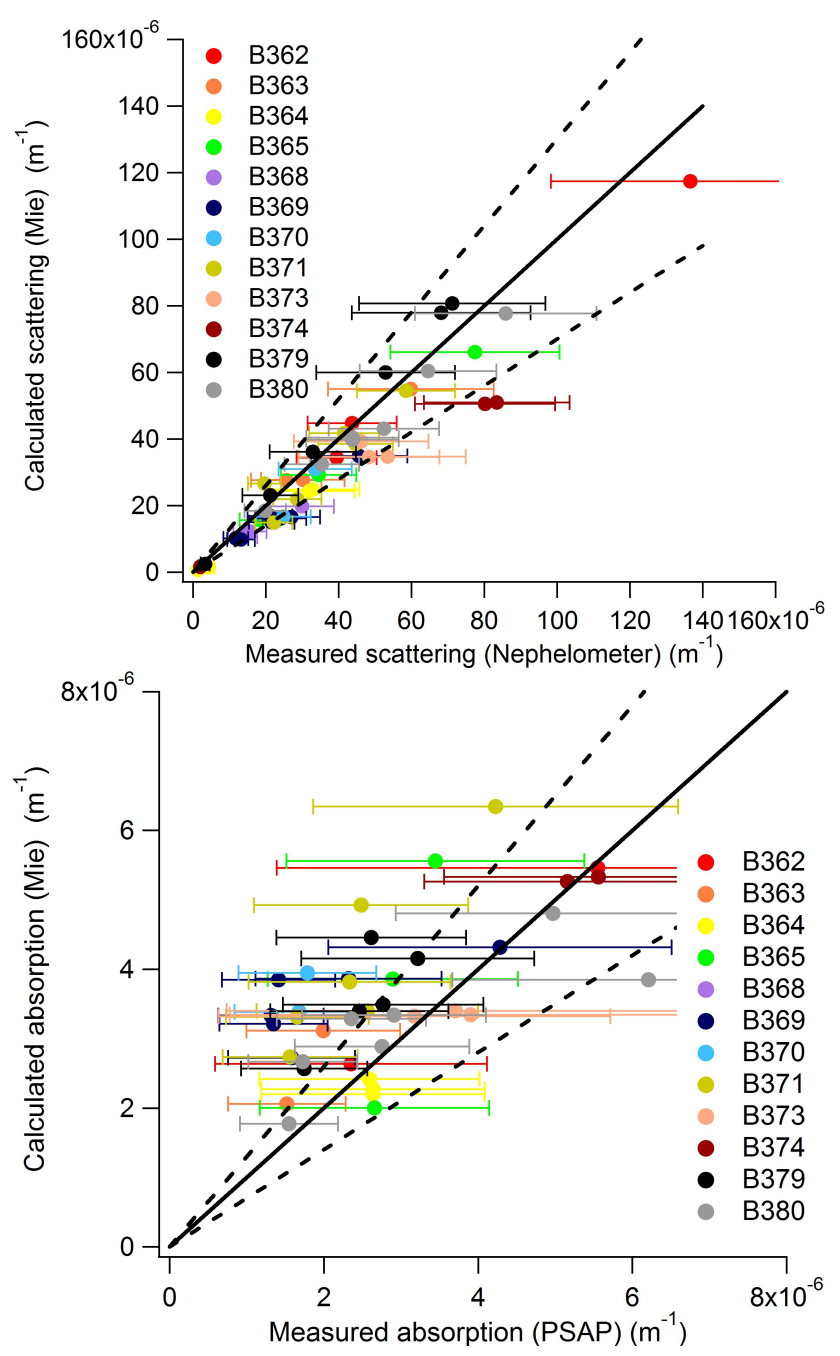

Fig. 8. Calculated versus measured scattering (a) and absorption (b) at $550 \mathrm{~nm}$ averaged for each run in every flight from EUCAARILONGREX. The one-to-one line is indicated (solid black) as are the $\pm 30 \%$ tolerances (dashed lines). Error bars show the uncertainty in measured scattering assuming a measurement uncertainty of $20 \%$ for the nephelometer and in-run variability ranging from 12-35\% in (a) and the uncertainty in measured absorption assuming a measurement uncertainty of $30 \%$ for the PSAP and in-run variability ranging from $16-47 \%$ in (b).

majority of the modelled values agree with the measurements within the considerable measurement uncertainties, we expect that the PSAP in fact itself over-estimates the absorption since the organic carbon concentration is relatively high (Lack et al., 2008). Indeed, considering the ratios of organic carbon to black carbon which range from 20 to 120 , and using the "all data" relationship from Lack et al. (2008) we might expect an over-estimate by between a factor of 2.5 and 5. Here our calculated absorption is higher than the PSAP measurement and thus if the PSAP measurement is itself an over-estimate (due to high organic fraction and measurement of absorption from larger sizes by the PSAP), the modelled absorption is far from correct.

Not-withstanding the large errors in the measured absorption - we will return to these in a moment - it is useful to consider reasons why the model could be over-estimating the absorption compared to measurements. The most likely issue concerns the imaginary part of the refractive index for black carbon and/or organic carbon. Considerable debate continues regarding the most appropriate $\mathrm{BC}$ refractive index (see e.g. Stier et al., 2007). Figure 9 considers two flights spanning the range of absorption seen and shows the impact of using two different refractive indices for BC, that in Hess et al. (1998) of 1.77-0.44i (solid squares) and that recommended by Stier et al. (2007) of 1.85-0.71i (solid upright triangles). The use of reduced absorption for $\mathrm{BC}$ does bring the modelled and measured absorption closer into agreement, however, the change is modest (less than 20\%). Having far more impact for this study is uncertainty in the imaginary component of the refractive index for organic carbon. Removing all absorption by organic carbon (as suggested in some previous studies) reverses the bias in the model results such that calculated absorption now underestimates the PSAP measurements. In addition, the slope of the dependency is altered for both flights, with the gradient becoming less steep and further from the $1: 1$ line. Retaining some weak absorption (halving the imaginary refractive index) of OC brings the model and measurements into better agreement in terms of both absolute closure and the gradient of the fit between models and measurements. Therefore it is possible to conclude that the organic aerosol measured during this campaign is moderately absorbing - although perhaps a little more absorbing than the rural HULIS of Dinar et al. (2008), and that for this aerosol mixture, this uncertainty is more important for modelling absorption than uncertainties in the BC refractive index. The extent to which this latter statement is more widely applicable is limited by the relative amounts of $\mathrm{OC}$ and $\mathrm{BC}$ in the aerosol. The BC effect is relatively weak here as the mass is relatively small, and contributes around $2.5 \%$ of the total AOD. In regions with high BC loadings, the uncertainty in its absorption is expected to be more significant for AOD measurements. However, it is important to remember that quantities other than AOD are also important; even in this case, $\mathrm{BC}$ plays a significant role in determining the absorption and the single scattering albedo.

However, the extent to which we can definitively constrain the refractive indices is significantly limited by the considerable uncertainties in measured absorption. Also shown in Fig. 9 is the impact of assuming no absorption by OC and an overestimate by PSAP of the measured absorption by a factor of around 2.5 (derived from ratio of $\mathrm{OC}$ and $\mathrm{BC}$ and Lack et al., 2008). This is shown by the red diamonds, and it is clear that the measured and modelled results can also be brought into agreement by making these adjustments, instead of assuming some absorption from OC. Thus it appears that despite the use of $\mathrm{BC}$ measurements to better constrain 

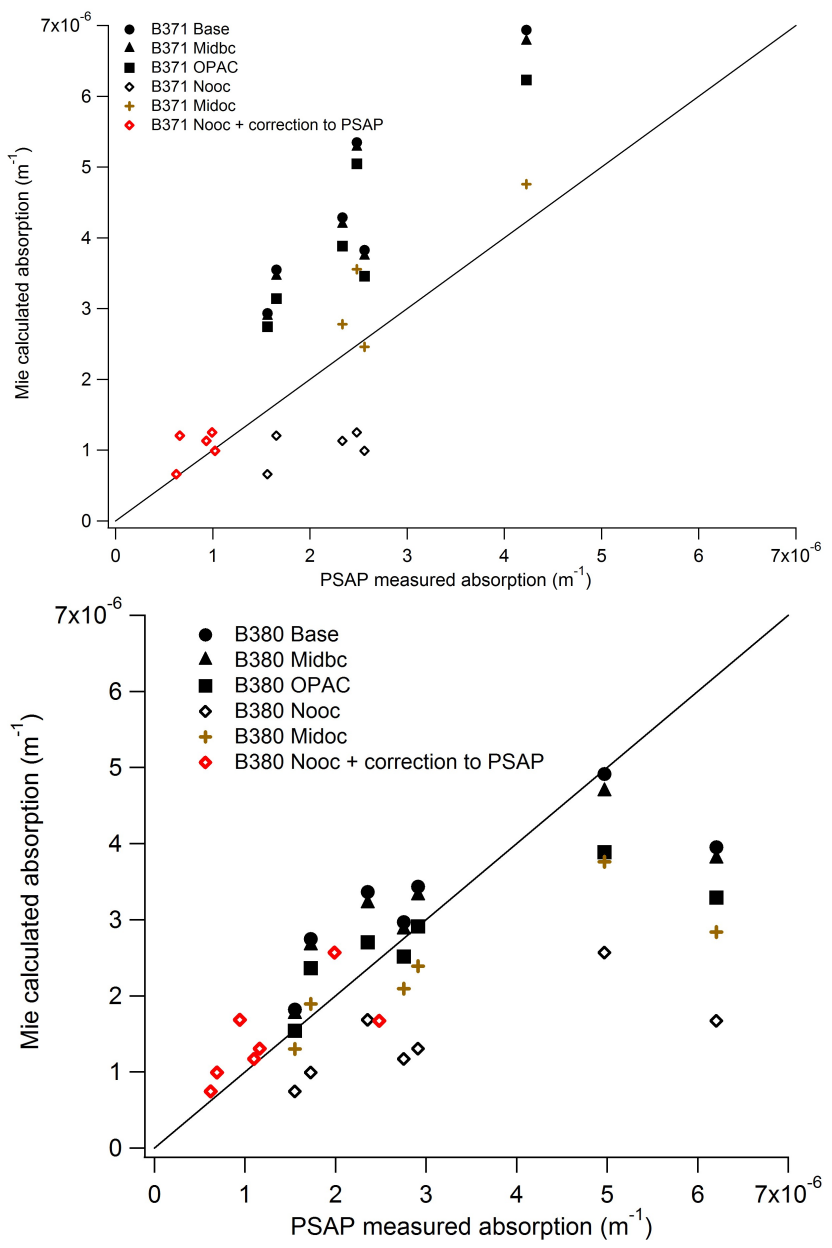

Fig. 9. Sensitivity of absorption closure to assumptions in refractive index of absorbing components for flights B371 (left-hand panel) and B380 (right-hand panel). "Base" is the control simulation as used elsewhere in the paper. "OPAC" refers to BC refractive indices from Hess et al. (1998), "Midbc" is the value from Stier et al. (2007). "Nooc" is a simulation with no absorption by organic carbon, whilst "Midoc" refers to an imaginary component for OC of 0.105 (half that in the Base case). The red diamonds represent the results of a "Nooc" simulation plotted against PSAP measurements that have been corrected assuming an overestimate of a factor 2.5 (based on methodology of Lack et al., 2008).

the optical property closure, we are prevented from inferring anything conclusive about the $\mathrm{OC}$ refractive indices by the uncertainty in our absorption measurements.

\section{Conclusions}

This study suggests that boundary layer aerosol optical properties in anthropogenically perturbed air masses over western Europe during EUCAARI-LONGREX were described by a mass extinction of $4.4 \pm 0.2 \mathrm{~m}^{2} \mathrm{~g}^{-1}$ (dry) and $5.6 \pm 0.3 \mathrm{~m}^{2} \mathrm{~g}^{-1}$ (ambient), a single scattering albedo of
$0.93 \pm 0.03$ and a scattering growth factor of 1.5 (range 1.23 to 1.63 ) at $80 \% \mathrm{RH}$. The main regional variations appeared to be the occurrence of relatively high SSA and enhanced growth factor in regions of high nitrate. These led to higher optical depths to the west of the region of study. The role of nitrate in determining optical and hygroscopic properties is of key importance to studies of the radiative effect and forcing of aerosols and many models have yet to include this component. The importance of nitrate in Europe has been confirmed during EUCAARI-LONGREX and may be expected to increase similarly in importance in other regions as sulphate concentrations decline in the future. It is paramount that we include nitrate aerosol in radiative forcing models and have adequate understanding of its optical properties.

Attempts to perform "optical closure" experiments by modelling absorption and scattering derived from chemical composition and size distribution measurements together with assumed refractive indices utilised the new measurements of $\mathrm{BC}$ on board the BAe-146 for the first time. It was possible to get good agreement (well within the $30 \%$ measurement uncertainty) between modelled scattering and nephelometer measurements at $550 \mathrm{~nm}$ - this suggests that our definition of the real part of the refractive index for the major components of EU aerosol are adequate (at least at this wavelength). However, the agreement for absorption was puzzling. Although the extent of the agreement was not inconsistent with estimates of uncertainty in the measured absorption, the model consistently appeared to over-estimate the measured absorption (which we expect itself to be an overestimate by some $20-30 \%$ ). This strongly suggests that the imaginary part of the refractive index of the absorbing aerosol components used in this study (and others) was too high. Due to the relatively small mass of $\mathrm{BC}$, the influence of uncertainty in $\mathrm{BC}$ refractive index was relatively small here. Reducing the OC absorption to zero did reverse the sign of the bias between model and measurements but also changed the slope of the relationship between model and measurements - pushing it further away from the $1: 1$ slope. An intermediate value captured both the magnitude and the variation more adequately. One potential conclusion is that in this region, despite some significant $\mathrm{BC}$ sources, it is the secondary aerosol material such as nitrate and oxidised organics that have a major impact on the aerosol optical properties and therefore on the radiative effect. It is important to emphasise, however, that this study focussed on the regional scale and therefore is not able to describe conditions near the surface or in urban regions. In those regions and other environments with larger BC mass fraction we would expect the influence of uncertainty in $\mathrm{BC}$ refractive index to be larger on the $\mathrm{ab}$ sorption. Indeed, measurements using the same instrumentation in urban outflow suggest that in these regions BC plays a much more important role (McMeeking et al., 2011b).

The SP2 measurements of BC, together with the wet nephelometer and AMS instruments used in this flight campaign offer an enhanced capability for performing optical closure 
studies across a range of aerosol, giving us the potential to better constrain optical properties and refractive indices used in forcing and climate models. However, conclusive quantification of the refractive index of organic carbon was thwarted in this case by the uncertainty in measurement of absorption by filter based measurements which are prone to over-estimates in situations such as EUCAARI-LONGREX when the OC component is substantial. The combination of state-of-the-art BC mass concentrations (as used on the FAAM BAe146), with more accurate absorption measurements (as used on some other airborne platforms) would indeed be a powerful tool for identifying the optical properties of aerosols that are required to accurately simulate their effect on radiation in weather and climate models.

Acknowledgements. This work was supported by NERC ADIENT project NE/E011101/1 and EUCAARI project 036833-2. Airborne data was obtained using the BAe-146-310 large Atmospheric Resesearch Aircraft [ARA] flown by Directflight Ltd and managed by the Facility for Airborne Atmospheric Measurements [FAAM], which is a joint facility of the Natural Environment Research Council [NERC] and the Met Office. Thanks are also expressed to $\mathrm{K}$. Turnbull for useful discussions regarding instrument corrections.

Edited by: P. Stier

\section{References}

Anderson, T. L. and Ogren, J. A.: Determining aerosol radiative properties using the TSI 3563 integrating nephelometer, Aerosol Sci. Technol., 29, 57-69, 1999.

Bates, T. S., Anderson, T. L., Baynard, T., Bond, T., Boucher, O., Carmichael, G., Clarke, A., Erlick, C., Guo, H., Horowitz, L., Howell, S., Kulkarni, S., Maring, H., McComiskey, A., Middlebrook, A., Noone, K., O’Dowd, C. D., Ogren, J., Penner, J., Quinn, P. K., Ravishankara, A. R., Savoie, D. L., Schwartz, S. E., Shinozuka, Y., Tang, Y., Weber, R. J., and Wu, Y.: Aerosol direct radiative effects over the northwest Atlantic, northwest Pacific, and North Indian Oceans: estimates based on in-situ chemical and optical measurements and chemical transport modeling, Atmos. Chem. Phys., 6, 1657-1732, doi:10.5194/acp-6-1657-2006, 2006.

Bond, T. C. and Bergstrom, R. W.: Light absorption by carbonaceous particles: an investigative review, Aerosol Sci. Technol. 40, 27-67, 2006.

Bond, T. C., Anderson, T. L, and Campbell, D.: Calibration and intercomparison of fliter-based measurements of visible light absorption by aerosols, Aerosol Sci. Technol., 30, 582-600, 1999.

Cai, Y., Montague, D. C., and Deshler, T.: Comparison of measureed and calculated scattering from surface aerosols with an average, size-dependent, and a time-dependent refractive index, J. Geophys., Res., 116, D02202, doi:10.1029/2010JD014607, 2011.

Canagaratna, M. R., Jayne, J. T., Jimenez, J. L., Allan, J. D., Alfarra, M. R., Zhang, Q., Onasch, T. B., Drewnick, F., Coe, H., Middlebrook, A., Delia, A., Williams, L. R., Trimborn, A. M., Northway, M. J., DeCarlo, P. F., Colb, C. E., Davidovits, P., and
Worsnop, D. R.: Chemical and microphysica characterization of ambient aerosols with the aerodyne aerosol mass spectrometer, Mass Spectrom. Rev., 26, 185-222, doi:10.1002/mas.20115, 2007

Chylek, P., Srivastava, V., Pinnick, R. G., and Wang, R. T.: Scattering of electromagnetic waves by composite spherical particles: Experiment and effective medium approximations, Appl. Opt., 27, 2396-2404, 1988.

Cook, J., Highwood, E. J., Coe, H., Formenti, P., Haywood, J. M., and Crosier, J.: A comparison of aerosol optical and chemical properties over the Adriatic and Black Seas during summer 2004: Two case-studies from ADRIEX, Q. J. Roy. Meteorol. Soc., 133, 33-45, 2007.

Cross E., Slowik, J., Davidovits, P., Allan, J., Worsnop, D., Jayne, J., Lewis, d., Canagaratna, M., and Onasch, T.: Laboratory and ambient particle density determinations using light scattering in conjunction with aerosol mass spectrometry, Aerosol Sci. Technol., 41, 343-359, 2007.

Dinar, E., Mentel, T. F., and Rudich, Y.: The density of humic acids and humic like substances (HULIS) from fresh and aged wood burning and pollution aerosol particles, Atmos. Chem. Phys., 6, 5213-5224, doi:10.5194/acp-6-5213-2006, 2006.

Dinar, E., Abo Riziq, A., Spindler, C., Erlick, C., Kiss, G., and Rudich, Y.: The complex refractive index of atmospheric and model humic-like substances (HULIS) retrieved by a cavity ring down aerosol spectrometer (CRD-AS), Faraday Discuss., 137, 279-295, 2008.

Edwards, J. E. and Slingo, A.: Studies with a flexible new radiation code. 1. Choosing a configuration for a large-scale model, Q. J. Roy. Meteorol. Soc., 122, 689-719, 1996.

Fiebig, M., Petzold, A.,Wandinger, U., Wendisch, M., iemle, C., Stifter, A., Ebert, M., Rother, T., and Leiterer, U.: Optical closure for an aerosol column: method, accuracy, and inferable properties applied to a biomass-burning aerosol and its radiative forcing, J. Geophys. Res., 107, 8130, doi:10.1029/2000JD000192, 2002.

Fierz-Schmidhauser, R., Zieger, P., Wehrle, G., Jefferson, A., Ogren, J. A., Baltensperger, U., and Weingartner, E.: Measurement of relative humidity dependent light scattering of aerosols, Atmos. Meas. Tech., 3, 39-50, doi:10.5194/amt-3-392010, 2010.

Gysel, M., Crosier, J., Topping, D. O., Whitehead, J. D., Bower, K. N., Cubison, M. J., Williams, P. I., Flynn, M. J., McFiggans, G. B., and Coe, H.: Closure study between chemical composition and hygroscopic growth of aerosol particles during TORCH2, Atmos. Chem. Phys., 7, 6131-6144, doi:10.5194/acp-7-61312007, 2007.

Hamburger, T., McMeeking, G., Minikin, A., Birmili, W., Dall'Osto, M., O’Dowd, C., Flentje, H., Henzing, B., Junninen, H., Kristensson, A., de Leeuw, G., Stohl, A., Burkhart, J. F., Coe, H., Krejci, R., and Petzold, A.: Overview of the synoptic and pollution situation over Europe during the EUCAARILONGREX field campaign, Atmos. Chem. Phys., 11, 10651082, doi:10.5194/acp-11-1065-2011, 2011.

Haywood, J. M., Bush, M., Abel, S., Claxton, B., Coe, H., Crosier, J., Harrison, M., MacPherson, B., Naylor, M., and Osborne, S.: Prediction of visibility and aerosol within the operational Met Office Unified Model. II. Validation of model performance using observational data, Quart. J. Roy. Soc., 134, 1817-1832, 2008. 
Hess, M., Koepke, P., and Schult, I.: Optical properties of aerosols and clouds: The software package OPAC, B. Am. Meteorol. Soc., 79, 831-844, 1998.

IPCC: Climate Change 2007: The Physical Science Basis. Contribution of Working Group I to the Fourth Assessment Report of the Intergovernmental Panel on Climate Change, edited by: Solomon, S., Qin, D., Manning, M., Chen, Z., Marquis, M., Averyt, K. B., Tignor, M., and Miller, H. L., Cambridge University Press, Cambridge, United Kingdom and New York, NY, USA, 2007.

Johnson, B. J. and Osborne, S. R.: Physical and optical properties of mineral dust aerosol measured by aircraft during the GERBILS campaign, Q. J. Roy. Meteorol. Soc., 137, 1117-1130, doi:10.1002/qj.777, 2011.

Johnson, D. W., Osborne, S. R., Wood, R., Suhre, K., Johnson, R., Businger, S., Quinn, P. K., Wiedensohler, A., Durkee, P. A., Russell, L. M., Andreae, M., O’Dowd, C., Noone, K., Namdy, B., Rudolph, J., and Rapsomanikas, S.: An overview of the Lagrangian experiments undertaken during the North Atlantic Aerosol Characterisation experiments (ACE-2), Tellus, 52B, 290-320, 2000.

Kotchenruther, R. A., Hobbs, P. V., and Heff, D. A., Humidifcation factors for atmospheric aerosols off the mid-Atlantic coast of the United States, J. Geophys. Res., 104, 2239-2251, 1999.

Lack, D., Cappa, C., Covert, D., Baynard, T., Massoli, P., Sierau, B., Bates, T., Quinn, P., Lovejoy, E., and Ravishankara, A. R.: Bias in fliter-based Aerosol Light Absorption Measurements due to Organic Aerosol Loading: Evidence from Ambient Measurements, Aerosol Sci. Technol., 42, 1033-1041, 2008.

McFiggans, G., Alfarra, M. R., Allan, J., Bower, K., Coe, H., Cubison, M., Topping, D., Williams, P., Decesari, S., Facchini, C., and Fuzzi, S.: Simplification of the representation of the organic component of atmospheric particulates, Faraday Discuss., 130, 341-362, 2005.

McMeeking, G. R., Hamburger, T., Liu, D., Flynn, M., Morgan, W. T., Northway, M., Highwood, E. J., Krejci, R., Allan, J. D., Minikin, A., and Coe, H.: Black carbon measurements in the boundary layer over western and northern Europe, Atmos. Chem. Phys., 10, 9393-9414, doi:10.5194/acp-10-9393-2010, 2010.

McMeeking, G. R., Good, N., Petters, M. D., McFiggans, G., and Coe, H.: Influences on the fraction of hydrophobic and hydrophilic black carbon in the atmosphere, Atmos. Chem. Phys., 11, 5099-5112, doi:10.5194/acp-11-5099-2011, 2011a.

McMeeking, G. R., Morgan, W. T., Flynn, M., Highwood, E. J., Turnbull, K., Haywood, J., and Coe, H.: Black carbon aerosol mixing state, organic aerosols and aerosol optical properties over the United Kingdom, Atmos. Chem. Phys., 11, 9037-9052, doi:10.5194/acp-11-9037-2011, 2011 b.

Moffet, R. C. and Prather, K. A.: In-situ measurements of the mixing state and optical properties of soot with implications for radiative forcing estimates, P. Natl. Acad. Sci., 106, 11872-11877, 2009.

Morgan, W. T., Allan, J. D., Bower, K. N., Highwood, E. J., Liu, D., McMeeking, G. R., Northway, M. J., Williams, P. I., Krejci, R., and Coe, H.: Airborne measurements of the spatial distribution of aerosol chemical composition across Europe and evolution of the organic fraction, Atmos. Chem. Phys., 10, 4065-4083, doi:10.5194/acp-10-4065-2010, 2010a.
Morgan, W. T., Allan, J. D., Bower, K. N., Esselborn, M., Harris, B., Henzing, J. S., Highwood, E. J., Kiendler-Scharr, A., McMeeking, G. R., Mensah, A. A., Northway, M. J., Osborne, S., Williams, P. I., Krejci, R., and Coe, H.: Enhancement of the aerosol direct radiative effect by semi-volatile aerosol components: airborne measurements in North-Western Europe, Atmos. Chem. Phys., 10, 8151-8171, doi:10.5194/acp-10-81512010, 2010b.

Ogren, J, A.: Comment on "Calibrations and Intercomparison of fliter-based measurements of Visible Light Absorption by Aerosols", Aerosol Sci. Technol., 44, 589-591, 2010.

Osborne, S. R., Wilson, A., and Rogers, S.: Description and first results of the wet nephelometer fitted to the FAAM BAe-146 research aircraft, OBR Technical Note No. 57, UK Met Office, Exeter, 2006.

Osborne, S. R., Haywood, J. M., and Bellouin, N.: In situ and remote-sensing measurements of the mean microphysical and optical properties of industrial pollution aerosol during ADRIEX, Q. J. Roy. Meteorol. Soc., 133, 17-32, 2007.

Petzold, A., Fiebig, M.,, Flentje, H., Keil, A., Leitner, U., ,Schröder, F., Stifter, A., Wendisch, M., and Wendling, P.:Vertical variability of aerosol properties observed at a continental site during the Lindenberg Aerosol Characterisation Experiment (LACE 98), J. Geophys. Res., 107, 8128, doi:10.1029/2001JD001043, 2002.

Quinn, P. K. and Coffman, D. J.: Local closure during the First Aerosol Characterisation Experiment (ACE-1): Aerosol mass concentration and scattering and backscattering coefficients, J. Geophys. Res., 103, 16575-16596, 1998.

Redemann, J., Russell, P. B., and Hamil, P.: Dependence of light absorption and single-scattering albedo on ambient relative humidity for sulfate aerosols with black carbon cores, J. Geophys. Res., 106, 27485-27495, 2001.

Rosenberg, P. D., Dean, A. R., Williams, P. I., Dorsey, J. R., Minikin, A., Pickering, M. A., and Petzold, A.: Particle sizing calibration with refractive index correction for light scattering optical particle counters and impacts upon PCASP and CDP data collected during the Fennec campaign, Atmos. Meas. Tech., 5, 1147-1163, doi:10.5194/amt-5-1147-2012, 2012.

Ryder, C. L., Highwood, E. J., Rosenberg, P., Trembath, J., Brooke, J., Bart, M., Dean, A., Banks, J., Brindley, H., Dorsey, J., McQuaid, J., and Washington, R.: The optical properties of Saharan dust aerosol and contribution from the coarse mode as measured during the Fennec 2011 aircraft campaign, in preparation, 2012.

Schmid, B., Ferrare, R., Flynn, C., Elleman, R., Covert, D., Strawa, A., Welton, E., Turner, D., Jonsson, H., Redemann, J., Eilers, J., Ricci,K., Hallar, A. G., Clayton, M., Michalsky, J., Smirnov, A., Holben, B., and Barnard, J.: How well do state-of-theart techniques measuring the vertical profile of tropospheric aerosol extinction compare?, J. Geophys. Res., 111, D05S07, doi:10.1029/2005JD005837, 2006.

Schwarz, J. P., Gao, R. S., Fahey, D. W., Thomson, D. S., Watts, L. A., Wilson, J. C., Reeves, J. M., Darbeheshti, M., Baumgardner, D. G., Kok, G. L., Chung, S. H., Schulz., M., Hendriks, J., Lauer, A., Karcher, B., Slowik, J. G., Rosenlof, K. H., Thompson, T. L., Langford, A. O., Lowenstein, M., and Aiken, K. C.: Single particle measurements of mid-latitude black carbon and light-scattering aerosols from the boundary layer to the lower stratosphere, J. Geophys. Res., 110, D16207, doi:10.1029/2006JD007076, 2006. 
Sciare, J., Oikonomou, K., Cachier, H., Mihalopoulos, N., Andreae, M. O., Maenhaut, W., and Sarda-Estève, R.: Aerosol mass closure and reconstruction of the light scattering coefficient over the Eastern Mediterranean Sea during the MINOS campaign, Atmos. Chem. Phys., 5, 2253-2265, doi:10.5194/acp-5-2253-2005, 2005.

Stephens, M., Turner, N., and Sandberg, J.: Particle identification by laser-induced incandescence in a solid-state laser cavity, Appl. Optics, 42, 3726-3736, 2003.

Stier, P., Seinfeld, J. H., Kinne, S., and Boucher, O.: Aerosol absorption and radiative forcing, Atmos. Chem. Phys., 7, 5237-5261, doi:10.5194/acp-7-5237-2007, 2007.

Tang, I. N.: Chemical and size effects of hygroscopic aerosols on light scattering coefficients, J. Geophys., Res., 101, 1924519250, doi:10.1029/96JD03003, 1996.

Toon, O. B., Pollack, J. B., and Khare, B. N.: The optical constants of several atmospheric aerosol species: ammonium sulphate, aluminium oxide and sodium chloride, J. Geophys. Res., 81, 57335748, 1976.

Topping, D. O., McFiggans, G. B., and Coe, H.: A curved multicomponent aerosol hygroscopicity model framework: Part 2 - Including organic compounds, Atmos. Chem. Phys., 5, 1223-1242, doi:10.5194/acp-5-1223-2005, 2005.
Turnbull, K.: PSAP Corrections: Amendment to MRF Technical Note No. 31., OBR Technical Note, No. 80, Met Office, August 2010.

Virkkula, A., Ahlquist, N. C., Covert, D. S., Arnott, W. P., Sheridan, P. J., Quinn, P. K., and Coffman, D. J.: Modification, calibration and a field test of an instrument for measuring light absorption by particles, Aerosol. Sci., Technol., 39, 68-83, 2005.

Weast, R. C. (Ed): CRC Handbook of Chemistry and Physics (67th edition), CRC press, Boca Raton, Florida, 1985.

Weingartner, E., Saathoff, H., Schnaiter, M., Streit, N., Bitnar, B., and Baltensperger, U.: Absorption of light by soot particles: Determination of the absorption coefficient by means of Aethelometers, Aerosol Sci., 34, 1445-1463, 2003.

Wex, H., Neususs, C., Wendisch, M., Stratmann, F., Koziar, C., Keil, A., Wiednsohler, A., and Ebert, M.: Particle scattering, backscattering and absorption co-efficients: An in-situ closure and sensitivity study, J. Geophys. Res., 107, 8122, doi:10.1029/2000JD000234, 2002. 